\title{
ASSESSING BENEFITS OF SLUM UPGRADING Programs in SeCOND-Best SetTings*
}

\author{
Basab Dasgupta and Somik V. Lall \\ Development Research Group, The World Bank, Washington DC 20433, USA
}

\begin{abstract}
Slum upgrading programs are being used by national and city governments in many countries to improve the welfare of households living in slum and squatter settlements. These programs typically include a combination of improvements in neighborhood infrastructure, land tenure, and building quality. In this paper, we develop a dynamic general equilibrium model to compare the effectiveness of alternative slum upgrading instruments in a second-best setting with distortions in the land and credit markets. We numerically test the model using data from three Brazilian cities and find that the performance of in situ slum upgrading depends on the severity of land and credit market distortions, and how complementary policy initiatives are being implemented to correct for these problems. Pre-existing land supply and credit market distortions reduce the benefit-cost ratios across interventions, and change the rank ordering of preferred interventions. In the light of these findings, it appears that partial equilibrium analysis used in typical costbenefit work overstates the stream of net benefits from upgrading interventions, and may in fact propose a misleading sequence of interventions.
\end{abstract}

JEL Classification: R21, R31, R38, I31.

Key Words: Slum upgrading, preexisting distortions, second best policies

\section{World Bank Policy Research Working Paper 3993, August 2006}

The Policy Research Working Paper Series disseminates the findings of work in progress to encourage the exchange of ideas about development issues. An objective of the series is to get the findings out quickly, even if the presentations are less than fully polished. The papers carry the names of the authors and should be cited accordingly. The findings, interpretations, and conclusions expressed in this paper are entirely those of the authors. They do not necessarily represent the view of the World Bank, its Executive Directors, or the countries they represent. Policy Research Working Papers are available online at http://econ.worldbank.org.

\footnotetext{
* This research has been funded by a World Bank Knowledge for Change (KCP) program grant "Dynamics of Slum Formation and Strategies to Improve Lives of Slum Dwellers." We thank Paulo Avila, Bob Buckley, Dean Cira, Mila Freire, Sonia Hammam, Hyoung Gun Wang and Christian Zimmerman for helpful comments. Author for correspondence: Somik Lall; Senior Economist, Development Research Group, World Bank. Email: slall1@worldbank.org.
} 


\section{Introduction}

Slum formation is occurring at unprecedented rates. A report by the United Nations shows that there are more than 1 billion slum dwellers worldwide, which is about 32 percent of the global urban population (United Nations 2003). While the representation of slum dwellers varies across regions, there is no doubt that slum formation is a daunting problem. Slum dwellers account for $71.9 \%$ of the urban population in sub-Saharan Africa, 58\% in South-central Asia, 36.4\% in East Asia and $32 \%$ in Latin America and the Caribbean. The UN Secretary General warns "if no serious action is taken, the number of slum dwellers worldwide is projected to rise over the next 30 years to about 2 billion" (United Nations 2003).

To address the growing problem of slum formation, many national and city governments, as well as international financial institutions have ongoing programs aimed at reducing the rate of future slum formation and improving the lives of existing slum dwellers. The World Bank has disbursed $\$ 14.3$ billion in shelter lending over the past 30 years, spread over 278 projects with an average size of almost $\$ 50$ million in 2001 dollars (Buckley and Kalarickal 2005). ${ }^{1}$ The UN Millennium Development Goals include “Cities without Slums" as Target 11, which specifically calls for significant improvement in the lives of at least 100 million slum dwellers by the year 2020. While there is an urgent need to scale up interventions that improve the quality of life for slum dwellers, there is little clarity on the types of interventions that are most effective or the relative cost effectiveness of alternate strategies.

\footnotetext{
${ }^{1}$ The World Bank's urban shelter lending portfolio has moved from financing project based sites and services and slum upgrading to now include broader housing policy and housing finance loans.
} 
Over several decades, strategies of national governments and development agencies to achieve better living conditions of slum dwellers have included sites and services programs, resettlement to new housing developments, and land titling. Initially, policies favored sites and services programs where infrastructure could be provided relatively cheaply on newly developed land. A major reason for the limited success of sites and services programs was the lack of access to housing finance for construction of the dwelling unit. With the persistence of large slum areas, limited success of slum relocation programs in terms of low retention rates and the realization that many slums could not be simply removed, slum upgrading projects have become more widespread.

Slum upgrading typically involves the provision of a package of basic services, which include clean water supply, sewage disposal, waste collection, housing, access roads, sidewalks, lighting, schools, health posts and community centers. An important component of these programs is regularizing properties in situations of insecure or unclear tenure. The underlying logic behind these interventions is that the poor cannot afford to make shelter improvements on their own due to a variety of income and credit constraints. The focus on explicit interventions rather than on cash transfers is that increases in disposable incomes for the poor may not translate into their access to basic services. This can be for several reasons, which include limited empowerment of the poor (include limited community cohesion and social networking among the poor) and time delays in expanding service coverage (information and coordination problems, supply constraints in network expansion, and weak incentives for providers to improve performance). 
In order to identify strategies that are useful for improving the lives of slum dwellers, there has been recent interest in evaluating the effectiveness of slum upgrading programs. As part of this, the World Bank recently commissioned a paper to provide guidance on how to estimate the impact of slum upgrading interventions (Field and Kremer 2005). Related to this effort, there have been several initiatives where baseline data are being collected so that they can be used to set up rigorous evaluations of project outcomes. The fly in the ointment in this evaluation strategy is the assumption that interventions happen in first-best settings. Similarly, much of the ex-ante cost-benefit estimation of these interventions also assumes market clearing. Clearly, this is not the case in most developing countries where there are pre existing distortions in the land (for example, excessive zoning, development controls) and credit (higher loan rates) markets. These pre existing distortions not only tend to reduce the cost effectiveness of interventions, but also may in fact change the welfare rank ordering across interventions. Thus, assessing the benefits of interventions without accounting for pre existing distortions may in fact be misleading. The performance of in situ slum upgrading depends on the severity of land and credit market distortions, and how complementary policy initiatives are being implemented to correct for these problems.

In this paper, we develop a dynamic general equilibrium model to compare the effectiveness of alternative instruments for improving the welfare of slum dwellers in a second-best setting with distortions in the land and credit markets. With four decisionmaking agents in our economy- households, developers, financial institutions and the government, we analyze how land or credit market distortions alter the rankings of different policy instruments. We also tested the effects of building caps and infrastructure 
bottlenecks, and get similar results. However, to maintain brevity, we do not include these findings in this paper. For the analysis, we lay out the residential location problem for poor urban households and analyze three types of interventions. These interventions include improvements in land, infrastructure, and building quality. ${ }^{2}$

To illustrate the analytical problem, we use examples from three Brazilian cities for which data have been collected in recent studies. The analytic strategy, however, is general and can be applied to a wide range of cities. We find that the presence of preexisting land supply and credit market distortions reduce the benefit cost ratios across interventions, and change the rank ordering of preferences across types of upgrading packages. In the light of these findings, it appears that partial equilibrium analysis used in a typical cost-benefit set up (which does not address pre existing distortions) may be overstating the stream of net benefits from interventions, and may, in fact, propose a misleading sequence of interventions. These findings are consistent with research in environmental economics (Bovenburg and Goulder 1996; Parry and Oates 1998) and public finance (Ballard and Fullerton 1992; Wildasin 1984), which suggest that the presence of pre-existing distortions changes the welfare impacts of new policy instruments.

The analysis is of particular relevance for Brazil as there are more than 1.3 million substandard housing units with 80 percent of them located in metropolitan areas (World Bank 2002). In February 2000, the Brazilian Government amended the constitution (Constitutional Amendment No. 26) and approved housing as a social right. The three-tier governmental support structure with the federal government at the helm of

\footnotetext{
${ }^{2}$ Bertuad and Brueckner (2005) also examine the welfare implications of one particular set of land market distortion - the Floor Area Ratio (FAR), arguing that this regulation encourages sprawl and increases commuting costs for edge residents.
} 
affairs, made the Ministry of Cities (MOC) as the responsible agency for establishing a national housing policy. The assurance of housing rights encompasses access to land tenure, basic public services and financial services.

Our study is outlined as follows. Following this introduction, Section 2 describes the model and equilibrium conditions. Section 3 discusses the impacts of slum upgrading programs. Section 4 concludes.

\section{Baseline Model}

In this section, we develop a general equilibrium model to examine the effectiveness of alternate slum upgrading policy instruments that can be used to improve household welfare. We first evaluate how these interventions perform in first-best settings, and then examine the effects of pre existing institutional and regulatory constraints on the effectiveness and relative rankings of these interventions (Section 3). These constraints include land supply constraints, ${ }^{3}$ infrastructure bottlenecks, and credit rationing.

We start with the assumption of a monocentric-closed city with no population growth. The model has four economic agents: households, developers, financial intermediaries and the city government.

\footnotetext{
${ }^{3}$ The increase in informal housing units between 1991 and 1998 (Morais 2000 based on PNAD/IBGE in World Bank Report No. 22032 BR, (2002), pp 16) shows the extent of housing deficit in Brazil. The report indicates that among 10 metropolitan regions, seven is reported to have over 50 percent increase in housing deficit with Recife and Curitiba having 52.8 and 143.4 percent respectively. This stylized fact supports our consideration of supply side bottleneck in housing market.
} 


\subsection{Households}

We consider an infinitely lived representative household who maximizes lifetime utility by consuming a composite good subject to a budget constraint. In period $t$, the household earns fixed wage income and distributes it between consumption and saving $\left(S_{t}\right)$ in period $t$. The composite consumption good in period $t$ is comprised of non-housing consumption, $\left(\mathrm{C}_{t}\right)$ and housing, $\left(\mathrm{H}_{\mathrm{t}}\right) .{ }^{4}$ We assume that each household consumes 1 unit of housing $\left(\mathrm{H}_{\mathrm{t}}=1\right)$ with specific attributes. These attributes are based on the household's hedonic preferences for building structure $\left(\mathrm{B}_{t}\right)$, land area $\left(\mathrm{L}_{t}\right)$ per house with particular location attributes such as infrastructure amenities $\left(A_{t}\right)$ and distance $\left(D_{t}\right)$ from the city center. 5

We assume that, with a given income $\left(\mathrm{w}_{\mathrm{t}}\right)$ and non-housing consumption $\left(\mathrm{C}_{\mathrm{t}}\right)$, households try to improve present quality of housing attributes $\left(\mathrm{q}_{\mathrm{t}}\right)$ over last period $\left(\mathrm{q}_{\mathrm{t}-1}\right)^{6}$. By definition, quality of housing is determined from the combination of different attributes present in a house. Therefore, ceteris paribus, household can improve quality housing by improving any of these attributes from previous period. Given the budget constraint, this implies that the household can decide its optimal demand for housing on the basis of her preferred combination of these attributes. The government usually steps in to assist when poor households are unable to make improvements due to limited affordability. The objective of various government programs for slum upgrading is either

\footnotetext{
${ }^{4} \mathrm{H}_{\mathrm{t}}$ is a bundle of housing attributes, which include the dwelling unit, infrastructure attributes, and neighborhood quality.

${ }^{5}$ See Clap (1980), Clapham et. Al (2004), Mayo (1986), Mills and Simenauer (1996), Reiff et al (2005), and Wolverton (2000) for details on hedonic estimation.

${ }^{6}$ As similar to the hedonic pricing literature (see Clapham et al (2004) for details) we incorporate the representative or standard dwelling quality $\left(\mathrm{q}_{\mathrm{t}-1}\right)$ for comparison. This standard can be set either by the households themselves under no government intervention or by the government as the social planner when necessary.
} 
to improve housing services or infrastructure so that it, at least, maintains previous quality level. We consider that the government makes a transfer payment, $T_{t}$, to the poor households to cover their housing quality enhancement program. Household savings $\left(S_{t}\right)$ are assumed to be deposited in the bank, and the gross return from this saving is (1

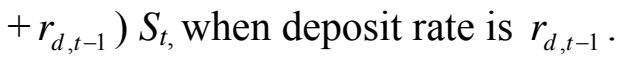

We also consider that better facilities are concentrated in the center of the city. Given income and non-housing consumption in period t, households' willingness to pay for each of the above-mentioned attributes in period $t$, thus, moves in tandem with the distance of the house from the city center, available infrastructure and housing facilities. Households incorporate these individual resource costs in a linear fashion to estimate their willingness to pay for a house. Households maximize their lifetime utility from the composite good as follows:

$$
\begin{aligned}
& \max _{A_{t}, L_{t}, S_{t}, B_{t}} V_{t}=\sum_{t=0}^{\infty} \beta^{t} \ln \left(C_{t}+\frac{q_{t}^{e}}{e}\right) \\
& \text { s.t. } \quad w_{t}+T_{t}+\left(1+r_{d, t-1}\right) S_{t-1}=C_{t}+p_{b, t} B_{t}+p_{l, t} L_{t}+p_{A, t} A_{t}+S_{t} \\
& \quad q_{t}=q_{t-1} A_{t}^{\xi_{1}} L_{t}^{\xi_{2}} B_{t}^{\xi_{3}} D_{t}^{1-\gamma}
\end{aligned}
$$

Where, $\beta$ is the discount factor bounded by $0 \leq \beta \leq 1$, $\mathrm{q}_{\mathrm{t}-1}$ is the representative or the standard quality from the previous period, $A_{t}$ represents infrastructure attributes, $L_{t}$ is land area, $B_{t}$ is building structure, and distance of housing from the center of the city is $D_{t}$. The value of the elasticity of substitution, e, determines households resource allocation between consumption and housing quality and is bounded within $[0,1]$. The parameters $\xi_{1}, \xi_{2}$ and $\xi_{3}$ represent the share of neighborhood attributes, land area per house and building structure respectively. The parameter $\gamma$ represents the shape of the 
city and commuting technology. For a concentric city, we adopt the value of $0 \leq \gamma \leq 2$ from Henderson and Venables (2004, pp. 4-5).

Assuming no growth and elasticity of substitution, e, being $1,{ }^{7}$ the Euler's equations with respect to

$$
\begin{aligned}
& A_{t}: p_{a, t}=\frac{\xi_{1}\left(q_{t}+\beta q_{t+1}\right)}{A_{t}} \\
& L_{t}: p_{l, t}=\frac{\xi_{2}\left(q_{t}+\beta q_{t+1}\right)}{L_{t}} \\
& B_{t}: p_{b, t}=\frac{\xi_{3}\left(q_{t}+\beta q_{t+1}\right)}{B_{t}} \\
& S_{t}: \beta=\frac{1}{1+r_{d, t}}
\end{aligned}
$$

The above prices represent household's willingness to pay or demand for respective components in order to maintain their housing quality.

\subsection{Developers ${ }^{8}$}

The developer is assumed to supply building structure and developed land in the form of housing $\left(\mathrm{H}_{\mathrm{t}}\right)$. We consider that developers use the available technology to transform land and building materials into residential units by incurring certain cost. We assume the market for housing to be perfectly competitive and the developer's marginal cost is exactly equal to price of each housing unit. The production function of housing is assumed to have constant return to scale of the following form:

$$
H_{t}=\psi_{t} L_{t}^{\alpha} B_{t}^{1-\alpha}
$$

\footnotetext{
${ }^{7}$ Elasticity of substitution is considered to be 1 for computational simplicity. It does not alter the basic results. However, the model can be calibrated for any value of e between $[0,1]$.

${ }^{8}$ Developers can be either in the public or private sector
} 
where, $H_{t}$ is the stock of housing in the economy, $L_{t}$ is land area in sq. mt., $B_{t}$ represents building structure. The parameter $\psi_{t}$ represents the technological parameter and is assumed to be 1 . With price per house in period $t$, $\mathrm{p}_{\mathrm{ht}}$, the developer's profit maximization problem can be written as

$$
\begin{aligned}
& \max _{t} \Pi_{t}=\left[p_{h t} L_{t}^{\alpha} B_{t}^{1-\alpha}-\left(1+r_{t}\right) R_{t}\right] \\
& \text { s.t. } \quad R_{t}=L_{t} p_{l, t}+B_{t} p_{b, t}
\end{aligned}
$$

where, $R_{t}$ is the total demand for finance by the developer to pay for the plot as well as materials. Based on the developer's maximization condition in the long run, supply of land and building structure per unit of housing are

$$
\begin{aligned}
L_{t} & =\frac{\alpha p_{h t}}{\left(1+r_{t}\right) p_{l, t}} \\
B_{t} & =\frac{(1-\alpha) p_{h t}}{\left(1+r_{t}\right) p_{b, t}}
\end{aligned}
$$

Notice that the developer's supply decision is inversely related to the loan rate, $r_{t}$. Therefore, any distortion in the credit market that affects the loan rate is expected to influence the land and building supply decision of the developer.

\subsection{Financial Intermediary}

We assume banks to be financial intermediaries that maximize profit in a perfectly competitive environment. Banks convert their entire deposits from households into loans towards the developer without any friction. In return, they charge a loan rate $r_{t}$. To make our model more general and compatible with our objective, we consider imperfections in the credit market. Such imperfection originates from the default vulnerability of the borrowers and expected recovery costs. This assumption is relevant for Brazil as well as most developing countries. According to a report by the World Bank (World Bank 2002), 
the housing finance system (HFS) could cater only 27 percent of total demand for loans of 23.7 million dollars during 1964-96. It also reports defaults in 30 percent of cases during this period.

To justify rationing in the credit market, we assume that the bank has a positive expected recovery cost, $r_{c}$, when a borrower defaults. Larger coverage exposes the bank to larger expected recovery costs and eventually higher loan rates. Incorporation of positive expected recovery cost in loan rates makes the banks' profit maximizing loan rate different from the market clearing loan rate, and leads to credit rationing in the market. Banks also use credit rationing to hedge against default risk. Thus, banks' profit maximization problem can be stated as

$$
\max _{R_{t}} \Pi_{t}^{B}=\omega r_{t} R_{t}-r_{d, t} S_{t}-r_{c} \omega R_{t}
$$

we get

$$
r_{t}=\frac{r_{d, t}}{\omega}+r_{c}
$$

where, $\omega$ is the fraction of total demand for loan being supplied by the bank. Banks decide this optimum fraction from the amount that satisfies bank's zero profit condition in the long run. The proportion $\omega$ lies between $[0,1]$. In our unconstrained world, $\omega$ is 1 . A value of $\omega<1$ indicates rationing in the credit market. As mentioned above, $\omega$ is 0.27 in the case of Brazil for HFS loans. 


\subsection{The Government}

The source of revenue of the city government is a three-tier system. ${ }^{9}$ The city government collects a part of its revenue from infrastructure facilities, $\left(A_{t}\right)$, provided to the households in the previous period. Also, at the beginning of each period the city government gets some exogenous funding $\left(\mathrm{G}_{t}\right)$ from the state and central government. With balanced budget assumption, the government budget constraint thus, takes the following form

$$
T_{t}=p_{a t-1} A_{t-1}+G_{t}
$$

Where, $T_{t}$ is the transfer to each household in period $t$ by the city government. The government makes this transfer to cover the cost of different intervention programs (e.g., supply of $A_{t}$, or in situ upgrading, etc) for housing quality enhancement. For simplicity we assume no extra sources of revenues for the city government. The duty of the city government is to allocate these funds into different development projects for the next period such as infrastructure and housing development. For welfare enhancement purposes the government can either take up any policy exclusively or its allocation strategy can be a combination of housing and infrastructure development.

\subsection{Equilibrium}

Equilibrium in this model economy is a sequence of prices $\left\{r_{t}, r_{d, t}, p_{h t}, p_{b, t}, p_{l, t}, p_{a, t}\right\}_{t=0}^{\infty}$,

allocations, $\left\{C_{t}, H_{t}, B_{t}, L_{t}\right\}_{t=0}^{\infty}$, stock of financial assets, $\left\{S_{t}, R_{t}\right\}_{t=0}^{\infty}$, and policy variables $\left\{T_{t}, A_{t}, G_{t}\right\}_{t=0}^{\infty}$, such that:

\footnotetext{
${ }^{9}$ We take this three tier system to represent the three tier government support structure in Brazil.
} 
1. The allocations and income solve the household's date $t$ maximization problem [Equation (1) - (3)], given prices and policy variables.

2. The allocations solve the firm's date $t$ profit maximization problem [Equations (9) and (10)], given prices and policy variables.

3. The stock of financial assets solves the bank's date $t$ profit maximization problem [Equation (13)], under credit rationing given prices and policy variables.

4. The loanable funds market equilibrium condition under credit rationing: $R_{t}=L_{t} p_{l, t}+B_{t} p_{b, t}$.

5. The housing market equilibrium condition satisfies $H_{t}^{d d}=f\left(L_{t}, B_{t}\right)$ for all $t$.

6. The government budget balances when $G_{t}+p_{t-1} A_{t-1}=T_{t}$.

After solving each agent's optimization problem we find from a system of equations with the same number of unknown variables that

- $\quad$ The discount factor $\beta$ can be estimated from Equation (7).

- $\quad$ The share of land per residence, $\alpha$, is estimated from Equations (5), (6), (11) and (12) as

$$
\alpha=\frac{\xi_{2}}{\xi_{2}+\xi_{3}}
$$

- $\quad$ From Equations (5) and (11) we get equilibrium value of housing quality as

$$
q=\left[\frac{\alpha}{\xi_{2}(1+r)(1+\beta)}\right] p_{h}
$$

This reduced form equation indicates the direct relationship between housing quality $\left(q_{t}\right)$ and house price $\left(p_{h}\right)$. 
- $\quad$ Given the input prices $\mathrm{p}_{\mathrm{l}}, \mathrm{p}_{\mathrm{b}}$ and housing price, $\mathrm{p}_{\mathrm{h}}$, we get equilibrium supply of land per residence by inserting Equation (17) into (5) as

$$
L=\frac{\alpha p_{h}}{(1+r) p_{l}}
$$

The amount of land developed and supplied by the developer decides the availability of land in the city. However, land availability is a function of availability of loan, $\omega$, through the loan rate, $\mathrm{r}$ (Equation 14).

- $\quad$ Based on available land and its fixed share in production, we get equilibrium building structure with given prices as

$$
B=\frac{(1-\alpha) p_{h}}{(1+r) p_{b}}
$$

- To maintain the same steady state housing quality (such that $q_{t}=q_{t-1}=\bar{q}$ ), the equilibrium values of land (Equation 18) and building structure (Equation 19) estimated above determine the optimum amount of infrastructure in the following way:

$$
A=\left[\frac{D^{\gamma-1}}{L^{\xi_{2}} B^{\xi_{3}}}\right]^{\frac{1}{\xi_{1}}}
$$

- $\quad$ From Equation (10), (18) and (19) we get equilibrium loan requirement per house for the construction of one unit residence as

$$
R=p_{l} L+p_{b} B
$$

\subsection{Estimating Equilibrium Parameter Values}

We quantify our model using data for three municipalities in Brazil - Brasilia, Curitiba and Recife, based on parameter values developed in recent research. From Serra et al (2004), we use total housing stock $\left(\mathrm{H}_{\mathrm{t}}\right)$, total urban developed land, land price per square 
meter $\left(\mathrm{p}_{1}\right)$ - both with and without infrastructure, to estimate the cost of land and cost of infrastructure per house. Using land prices, both with and without infrastructure facilities, we estimate the price of infrastructure amenities per unit of land (in square meters) and then convert this into corresponding average costs per house. These estimates are provided in Table 1 . The average construction cost per house $\left(B_{t} p_{t}\right)$ and total cost per house $\left(\mathrm{p}_{\mathrm{h}}\right)$, have been taken from World Bank (2002). ${ }^{10}$ That report also shows state level per capita expenditures on urban development in Brazil. The amount of land, infrastructure and building structure per house is considered as the units of respective assets and unit prices have been adjusted accordingly (see Table 1 for details).

From Equation (17), housing quality is directly related to price, given the parameter values $\alpha, \beta$ and loan rate, $\mathrm{r}_{\mathrm{t}}$. This corroborates our consideration of the share of each resource in total cost as their respective shares in quality. From this, we can assume that the share of land $\left(\xi_{2}\right)$, building $\left(\xi_{3}\right)$ and infrastructure $\left(\xi_{1}\right)$ in housing quality will be similar to their relative contributions to housing price. Table 2 presents the estimated parameter values from our model. Based on the parameter values given in Table 2, we estimate the equilibrium values of the following variables (presented in Table 3).

The above steady state values indicate the requirements of each resource to maintain the equilibrium housing quality at the city center $(D=1$ mile around the center). In the following section we calibrate our model and discuss the demand for each intervention in a first best setting, and then evaluate the change in demand for these interventions in the presence of various market distortions. For our numerical analysis, we consider three different situations with sub optimal housing quality. The steady state

\footnotetext{
${ }^{10}$ Table 36: Cost Break Down of Urban Upgrading, Recife, 1998 (pp. 71)
} 
value of quality derived from our model may have quality equivalence of $1.25,1.5$ and 1.75 respectively with respect to each of these substandard situations. These three hypothetical situations help us understand how demand for alternate inputs changes in order to reach the steady state equilibrium quality level. Based on these changes, we also estimate the social welfare to cost ratio for each government intervention and rank them accordingly to identify the best possible intervention in a constrained setting. The social welfare to cost ratio has been presented as the welfare gain per unit of money (real for Brazil) spent on the respective resource.

\section{Impacts of Slum Upgrading}

In this section we start our analysis with the assumption that the government uses slum upgrading to improve welfare of the urban poor. These welfare programs mainly focus on improving housing quality, which will improve quality of life for households living in sub-standard residential units. As mentioned earlier, we consider three such substandard situations. According to our consideration, the steady state has a quality equivalence of $1.25,1.5$ and 1.75 respectively as compared to these three substandard situations. The government intervenes to improve social welfare from these inferior situations to the steady state equilibrium. Given the fixed consumption of non-housing items, the government can improve welfare to the steady state standard by improving land availability, up grading building structure, or improving infrastructure facilities. These improvements can be done in situ - without relocating the households from their current dwelling units, or may involve relocation of households to areas where more land is available. In principle, relocation of households away from the city center or CBD will 
increases their demand for alternative resources to maintain the same welfare level. In what follows is a comparison of social welfare and cost between in-situ upgrading and relocation of households. We calibrate our model for different distances $\left(D_{t}\right)$ and quality equivalence (k). ${ }^{11}$

\subsection{In-Situ Upgrading}

The following analysis represents government's option for In Situ upgrading. ${ }^{12}$ Under this policy the government provides land to households, who, in turn, upgrade their own house with available loans from the bank. Public interventions may also focus on infrastructure and building quality. We compare the changes in social welfare to cost ratios and demand for resources under In Situ upgrading in order to find out ordering of each intervention. Next, we compare In Situ upgrading to relocation strategies. We also examine how the social welfare of various improvements fares in the presence of pre existing distortions. When the government allocates resources to households to achieve the equilibrium target, it produces different outcomes under market distortions. For example, when the land market is distorted, the government can intervene on the supply side and address this problem. However, if the distortion in the land market is transmitted from the credit market, then only addressing distortions in land market will not help unless the imperfections in credit market are also corrected.

\footnotetext{
${ }^{11}$ The methodology for estimating social welfare and requirements of different interventions to reach the equilibrium welfare from our substandard situation is provided in the appendix.

${ }^{12} \mathrm{We}$ consider 1 instead of 0 miles from the center to define the center of the city in order to avoid computational complexities.
} 
Table 4 provides the respective investments required for each intervention at various quality equivalence, $k$. We calibrate these resource requirements for different quality equivalence targets as mentioned earlier.

Table 5 shows the ordering of social welfare to cost ratio when the government opts for upgrading In Situ. Based on this, the social planner ranks each policy accordingly. According to this Table, the most effective policy for Brasilia should be building upgrading as compared to land titling or infrastructure for small or medium sized interventions $(\mathrm{k}=1.25,1.5)$. However, when large-scale improvements are needed (say $\mathrm{k}=1.75$ ), building upgrading will no longer be the best policy to improve quality. Rather, increasing land supply becomes most effective strategy. Given our set up infrastructure development is never the best option for Brasilia.

For the other two cities, however, infrastructure appears to be the best strategy relative to the other two interventions for any degree of quality enhancement. A closer look suggests that the second and the third ranked policies interchange places for higher level of quality equivalence. Apparently, in a perfect world, one can survive without caring much about this reshuffling between second and third ranks. However, in a world with infrastructure bottlenecks, it turns out to be more crucial for the social planner in picking up the second best.

Along with Table 5, a closer look at Figure 1 (the curve with distance $=1$ mile) suggests that the relationship between the demand for land and infrastructure in Brasilia is perfectly inelastic. This indicates that even a very large change in infrastructure may not be able to maintain the overall quality at the same level. We find similar relationship 
between building upgrading and infrastructure in Brasilia. Alternatively, we can support why infrastructure development is most preferred in Curitiba or Recife.

From Figure-1, we see that the demand for infrastructure in these two cities is more inelastic (see $\mathrm{C}_{1}$ and $\mathrm{R}_{1}$ ) before the point of inflexion is reached. The household is ready to substitute any amount of land in exchange for one unit of infrastructure to cross this threshold value of infrastructure requirement.

\subsection{Relocation Strategies}

We now look at a government's policy, which includes relocation from the center and compare it with the In Situ program described above. For this analysis, we assume that the government fixes its quality equivalence target at 1.25 . One way to relocate the poor successfully is by providing them with more land or improved facilities that will leave them no worse off than in their present location. Table 6 shows the corresponding change in demand for each intervention between in situ upgrading and relocation at different distances.

Table 7 compares the social benefit cost ratios between In Situ upgrading and relocation of households at various distances in Brasilia, Curitiba and Recife. As stated earlier, the benefit cost ratio has been presented in this table as welfare gain per real spent on a particular resource under different inventions. The Table shows that the social benefit cost ratio drops drastically due to a policy shift from In Situ upgrading to relocation. Further the social welfare-cost ratio of each intervention reduces with an increase in distance from the city center. 
Interestingly in Brasilia, improving building structure turns out to be best solution over land supply or infrastructure improvements under in situ program with steady state quality equivalence 1.25 . However, under relocation programs, land supply becomes the best policy for same level of quality equivalence and remains the best option with increase in distance. For the other two cities, the best solution is infrastructure development in both, in situ as well as relocation. However, similar to higher quality equivalence, the second and third ranked policies inter change places from in situ to relocation. The significance of this outcome becomes prominent under market distortion for infrastructure. In that case, due to unavailability of the first best solution, the second best policies will be different between the in situ and relocation programs.

Figure 1 suggests that given the infrastructure facilities, the demand for land shifts vertically upward quite significantly in each city due to a shift in policy of in situ upgrading to one that involves relocation of households. The gap between the two curves in each figure indicates the effect of increasing distance between the residence and the center of the city on substitution between infrastructure and land.

\subsection{Pre Existing Distortions: Land Supply Constraints}

The analysis so far assumes that there are no pre existing distortions that could influence the performance of slum upgrading. However, in practice there are many binding constraints such as unresponsive land supply and credit rationing, which make it important to assess slum-upgrading instruments in a second best setting. In this section, we examine the implications of a small set of pre existing distortions. We start by examining the effect of constrained land supply, which effectively means that the 
availability of developable land is fixed. ${ }^{13}$ Therefore it is not possible for the government to supply additional land to slum dwellers as citywide land supply is seriously constrained. When land supply is constrained, market price are expected to bid up significantly -- depending upon the severity of the supply problem, and leads to a decrease in the benefit cost ratios of government interventions (see Proposition 1).

Proposition 1: The benefit-cost ratio decreases due to land supply constraints.

Proof: From the relationship between quality and the residence attributes, $q_{t+1}=q_{t} A_{t}^{\xi_{1}} L_{t}^{\xi_{2}} B_{t}^{\xi_{3}} D_{t}^{1-\gamma}$ and to maintain the same quality, $\bar{q}=q_{t}=q_{t+1}$ we get from Equation (6) that $p_{l, t}=\frac{\xi_{2}(1+\beta) \bar{q}}{L_{t}}$

Now, if $\mathrm{L}_{\mathrm{t}}$ is reduced such that $\mathrm{L}_{1 \mathrm{t}}<\mathrm{L}_{\mathrm{t}}$, then

$$
p_{1 l}=\frac{\xi_{2}(1+\beta) \bar{q}}{L_{1 t}}>\frac{\xi_{2}(1+\beta) \bar{q}}{L_{t}}=p_{l} .
$$

Given the marginal utility from land, $\uparrow P_{l} \rightarrow \downarrow \frac{M U_{\text {Land }}}{P_{l}}$ QED

In such situations with a binding land supply constraint, the steady state quality can be maintained by increasing supply of building or infrastructure. We prove that under such binding conditions, the household demands more building structure per unit increase in distance than the situation without any land supply constraint (see Proposition 2).

\footnotetext{
${ }^{13}$ Land supply constraints could be both due to natural factors (elevation, location, etc) as well as policies (restrictive land use and zoning)
} 
Proposition 2: The rate of change in demand for building quality with increase in distance is positive and the rate of change is higher under land supply constraints.

Proof: From the relationship between building with land and infrastructure, given quality, we get

$$
\begin{aligned}
& B=\left[\frac{D^{\gamma-1}}{A^{\xi_{1}} L^{\xi_{2}}}\right]^{\frac{1}{\xi_{3}}} \\
& \frac{\delta B}{\delta D}=\left[\frac{(\gamma-1) D^{\gamma-2}}{A^{\xi_{1}} L^{\xi_{2}}}\right]^{\frac{1-\xi_{3}}{\xi_{3}}}>0 \text { \{since } \gamma>1 \text { and A, L, D >0 }
\end{aligned}
$$

Now, if the available land per residence is $\mathrm{L}_{1}$ such that $\mathrm{L}_{1}<\mathrm{L}$, then $\left[\frac{(\gamma-1) D^{\gamma-2}}{A^{\xi_{1}} L_{1}^{\xi_{2}}}\right]^{\frac{1-\xi_{3}}{\xi_{3}}}>\left[\frac{(\gamma-1) D^{\gamma-2}}{A^{\xi_{1}} L^{\xi_{2}}}\right]^{\frac{1-\xi_{3}}{\xi_{3}}}$ QED

We find same results for the change in demand for infrastructure under such distortion.

Figure 2 represents the effects of land supply constraints on the demand for building structure to maintain the steady state standard. The curves show that the household's demand for building quality improvement increases in an exponential fashion with increase in distance between the residence and the center of the city. The problem gets exacerbated in the presence of land market distortions. The gap between the two curves in each figure indicates the effect of land market distortion on demand for building structure due to each unit increase in distance between residence and the center of the city. We find that the effect is severe in Brasilia (from B-1 to B-2) and modest in Recife (R-1 to R-2) and in Curitiba (from C-1 to C-2).

The increase in demand for infrastructure with an increase in distance between the residence and the center shows a difference in preferences across three cities. While the demand for infrastructure in Brasilia is almost perfectly elastic with respect to distance, it shows that households adjust their housing quality by demanding more infrastructures in Curitiba and Recife. However, the reactions of households in the presence of land market 
distortion are not same in these two cities (Figure 3). The gap between the two curves in each figure indicates the effect of land market distortion on demand for infrastructure for each unit increase in distance between residence and the center of the city.

The higher marginal utility of land in Brasilia makes it easier under no land supply constraint to reach the required quality even with slight improvement in land availability per unit of housing (see Table 8). However, under land scarcity, when provision of extra land is not possible, the government is left with the two other options. In such a situation the second best option for Brasilia should be improving building quality. The situation does not arise in the case of Curitiba and Recife since infrastructure development remains the most effective options under land supply constraint.

Table 9 shows the changes in demand for building or infrastructure under binding land constraint. To keep the household at the same welfare level, resource requirements increase dramatically with land supply constraints.

\subsection{Pre Existing Distortions: Credit Rationing}

From our model, we find that land supply or housing quality improvement decisions are a function of the loan rate. Thus, when credit market imperfections distort the interest rate we can expect a transmission of such a distortion in resource markets that are dependent on the loan rate. In this part of the analysis, we examine how credit market imperfections translate into supply side bottlenecks in the land and housing markets. 
Earlier in this paper, we mentioned that the housing finance system (HFS) extended loans to about 27 percent of 23.7 million requirements between 1964 and 1996 (World Bank 2002). In the same report it has also been reported how the housing deficit increased from 1991 to 1998 . We are interested in putting these pieces together and use our analytic framework to find out whether credit market imperfections influence the functioning of the land market.

In our model we assume that developers use bank loans to fund new land development and purchase building material. As a result, credit rationing hinders land development and construction by developers.

Proposition 3: Stringent credit rationing distorts other resource markets.

Proof: From the developers optimization problem we get that $L_{t}$ and $B_{t}$ are inversely related to the bank loan rate, $\mathrm{r}_{\mathrm{t}}$.

$$
\begin{aligned}
L_{t} & =\frac{\alpha p_{h t}}{\left(1+r_{t}\right) p_{l, t}} \\
B_{t} & =\frac{(1-\alpha) p_{h t}}{\left(1+r_{t}\right) p_{b, t}}
\end{aligned}
$$

Also, from bank's optimization we get the loan rate is inversely related to fraction of total demand for credit supplied, $\omega$ as $r_{t}=\frac{r_{d, t}}{\omega}+r_{c}$.

Now, given $\mathrm{r}_{\mathrm{dt}}$ and $\mathrm{r}_{\mathrm{c}}$, as $\lim _{\sigma \rightarrow 0} \Rightarrow r_{t} \uparrow \Rightarrow \mathrm{L}_{\mathrm{t}}, B_{t} \downarrow \mathrm{QED}$

Proposition 3 shows that stringent credit rationing leads to distortions in the land market. In other words, land or housing supply decisions are constrained due to scarcity 
of developer finance. Table 10 shows how stringent credit rationing reduces the equilibrium land supply.

Figure 4 shows the effect of credit rationing on the change in supply of land. The curves show that credit rationing affects land supply in the same fashion as a land market distortion does. This implies that the imperfection in the credit market transmits to the land market and creates supply side bottlenecks.

Figure 5 shows how stringent credit rationing influence demand for resources such as land under a relocation program. B-1, R-1 and C-1 represent land supply when the loan rate is in equilibrium for Brasilia, Recife and Curitiba respectively. B-2, R-2 and C-2 represent land supply in the same cities under a higher loan rate. We see that the demand for land increases as a households moves from the city center to the periphery. This reflects the compensating variation in terms of land provision required to make the household no worse off as it moves out of its present location. The gap between the two curves in each figure (without and without credit rationing) indicates a credit market distortion effectively lowers the availability of developed land and exacerbates the unmet demand for land. From this analysis, it becomes evident that it is difficult to address land market problems without evaluating constraints in linked markets. Rationing in the credit market transmits similar distortions in the housing supply decision of developers.

\section{Conclusions}

There is increasing emphasis on the importance of slum upgrading instruments as a sustainable approach to improve the lives of slum dwellers. However, there is no consensus of what particular set of instruments works best, and how the effectiveness of 
alternate instruments changes when there are pre existing distortions in the land and credit markets. One of the objectives of our paper is to provide a more realistic assessment of what upgrading projects are likely to achieve if they are not part of a larger set of reforms that relax various distortions that hinder the functioning of the land and housing markets.

In this paper, we develop a dynamic general equilibrium model which includes households, developers, financial institutions and the government to evaluate the effectiveness of alternative instruments. Our findings are based on data from three Brazilian cities, but the approach developed here can be generalized and is relevant for most developing countries where land and housing markets are subject to distortions from excessive zoning and development controls.

We believe that there are three main reasons that the general equilibrium approach we propose here will provide better insights relative to a partial equilibrium assessment of slum improvement programs. First, typical partial equilibrium analysis is based on a households' marginal benefit and marginal cost without taking supply side constraints into account. Under in situ upgrading, it is usually assumed that households can keep increasing their consumption of one resource so long the marginal benefit exceeds the marginal cost (see for example, Heikkila 2004 who proposes a conceptual framework for application to Brazilian cities). The argument is difficult to defend if there are supply side bottlenecks. Second, marginal benefits of program interventions are calculated from a households' utility function, while the marginal cost is based on the government's expenditure / cost function. Fulfilling individual household demand (from their assessment of marginal benefits), solely based on their preferences may not yield a 
socially optimal solution. This discrepancy requires that the problem be recast in social benefit- social cost framework. Third, results from a general equilibrium framework improve upon partial estimates as it becomes possible to assess the reaction of various decision makers - households, government, and financial intermediary - to every policy shock For example, we show how a developer's or household's decision is motivated by a decision taken in the banking sector.

A comparison on upgrading in situ vs. involving relocation based on our model shows that the social benefit cost ratios across interventions drop dramatically if households are relocated from their original locations. The situation is made worse if there are pre existing land market distortions. The welfare analysis presented here suggests that these pre existing distortions not only tend to reduce the cost effectiveness of individual instruments, but also in fact change the welfare rank ordering across interventions. Thus, assessing the benefits of interventions without accounting for pre existing distortions is likely to be misleading. Further, the choice of preferred instrument (infrastructure, housing quality, land provision) depends on city specific characteristics and the severity of the underlying supply side bottlenecks.

We also find that distortions are transmitted across markets - for instance, land and building supply decisions of developers are a function of interest rates and any distortions in the credit market that increase effective interest rates also reduce land and housing supply. Thus distortions in the credit market exacerbate constraints in the land market. In this context, the effectiveness of project level upgrading interventions is likely to be enhanced if these are accompanied by institutional and regulatory reforms. 


\section{References}

Amann, E and W. Baer (2005): Economic Orthodoxy Versus Social Development? The Dilemmas Facing Brazil's Labor Government, Working paper 05-0108, Department of Economics, University of Illinois at Urbana-Champaign.

Ballard, C and D. Fullerton 1992. Distortionary Taxes and the Provision of Public Goods. The Journal of Economic Perspectives, 6, 3. 117-131.

Bertaud, A. and J. Brueckner (2005), "Analyzing Building Height Restrictions: Predicted Impacts and Welfare Costs," Regional Science and Urban Economics, 35, 109-125.

Bovenburg, A. L. and L. H. Goulder (1996) "Optimal Environmental Taxation in the Presence of Other Taxes: General- Equilibrium Analyses." The American Economic Review, 86, 4 985-1000.

Buckley R. and J. Kalarickal eds (2005). Thirty years of World Bank Shelter Lending: What Have We Learned? World Bank.

Clapham E, P. Englund, J. Quigley and C. L. Redfearn (2004): Revisiting the past: Revision in Repeat sales and Hedonic Indexes of House Prices, Working Paper No. W04-005. Fisher Center for Real Estate and Urban Economics, University of California, Berkeley.

Field, E and M. Kremer (2005) Impact Evaluation for Slum Upgrading Interventions. World Bank

Haurin, D., P. Hendershott and D. Kim (1991): Local House Price Indexes: 1982-1991, Journal of the American Real Estate and Urban Economics Association, 19, 451-72.

Heikkila, E. (2004) "Conceptual Framework: Evaluation of Policy Alternatives For Promoting Equitable Access to Urban Land in Brazil", World Bank - Cities Alliance-IPEA, Enabling Strategy for Moving Urban Upgrading to Scale in Brazil.

Hendershott, P and T. Thaibodeau (1990): The Relationship between Median and Constant Quality House Prices: Implications for Setting FHA loan limits, Journal of the AREUEA, 18, 323-34.

Henderson, J. V and A. J. Venables (2004) The Dynamics of City Formation: Finance and Governance, UK ESRC Centre for Economic Performance at LSE.

Mayo, S. K. (1986) "Sources of Inefficiency in Subsidized Housing Programs: A Comparison of U.S. and German Experience", Journal of Urban Economics, 20, 229-249.

Mills, E. and R. Simenauer (1996): "New Hedonic Estimates of Regional Constant Quality House Prices", Journal of Urban Economics, 39, 209-15.

Reiff, L. O, and A. L. Barbosa (2005). Housing Stock in Brazil: Estimation Based on a Hedonic Price Model, BIS Papers No. 21, Real Estate Indicators and Financial Stability, pp.257.

Parry, I W H and W. Oates (1998): Policy Analysis in a Second Best World. RFF Discussion Paper 98-48. Resources for the Future. 
Serra, M. V, D. E. Dowell, D. Motta and M. Donovan (2004): Urban land markets and Urban Land Development: An Examination of three Brazilian Cities: Brasilia, Curitiba and Recife, working paper 2004-03, Institute of Urban and Regional Development, University of California at Berkeley.

United Nations (2003) The Challenge of Slums: Global Report on Human Settlements. UN HABITAT, Nairobi.

Wildasin, D. (1984): On public goods provision with distortionary taxation. Economic Inquiry $22,2227-43$

Wolverton, M. L. (2000): Hedonic Estimates of Regional Constant Quality House Prices, American Real Estate Society.

World Bank (2002). Brazil Progressive Low-Income Housing: Alternatives for the Poor, Report no. 22032 BR, World Bank LAC FPSI. 
Table 1: Resource Availability, Corresponding Unit Resource Price and Total Costs/house

\begin{tabular}{|c|c|c|c|}
\hline & Brasilia \pm & Curitiba & Recife \\
\hline Total cost/ house (in Reais) & 7185 & 7185 & 7185 \\
\hline Availability of Building structure/House (in sq. mt) & 32 & 32 & 32 \\
\hline Cost of building structure/house (in Reais) & 2800 & 2800 & 2800 \\
\hline Unit Land price with infrastructure ( in Reais/ sq. mt) & 164 & 109 & 102 \\
\hline Unit Land price without infrastructure (in Reais/ sq. mt) & 157 & 38 & 44 \\
\hline $\begin{array}{l}\text { Unit Price of infrastructure (in Reais/ sq. mt) } \\
=[\text { land price with infra - land price without infra }]\end{array}$ & 7 & 71 & 58 \\
\hline Availability of Land area/house ( in sq. mt)* & 26.74 & 40.23 & 42.99 \\
\hline Cost of land/house (price of land without infra * land area/house) & 4197.84 & 1528.72 & 2395 \\
\hline Cost of infrastructure/ house & 187.17 & 2856.28 & 1990 \\
\hline Ratio of infrastructure cost $/$ house cost $\left(\mathrm{p}_{\mathrm{a}} / \mathrm{p}_{\mathrm{h})}\right)$ & 0.026 & 0.397 & 0.277 \\
\hline Ratio of land cost/ house cost $\left(\mathrm{p}_{\mathrm{l}} / \mathrm{p}_{\mathrm{h}}\right)$ & 0.584 & 0.213 & 0.333 \\
\hline Ratio of building cost/house cost $\left(\mathrm{p}_{\mathrm{b}} / \mathrm{p}_{\mathrm{h}}\right)$ & 0.389 & 0.389 & 0.389 \\
\hline Credit availability $\omega$ & 0.27 & 0.27 & 0.27 \\
\hline
\end{tabular}

Source: Land price/ square mt, with and without infrastructure, has been taken from Serra et al (2004), Table 24. Total cost of a residence and building structure cost (cost of bricks plus materials for a 32 sq.mt structure) is taken from 'Table 36: Cost Break Down of Urban Upgrading, Recife, 1998 (pp. 71)', in Report No. 22032 BR, Brazil Progressive Low-Income Housing: Alternatives for the Poor that reports the COHAB estimates based on Habitat-Brazil projects in the Recife Metropolitan Region.

Note 1: Availability of Land area/house = total cost of land plus infrastructure/ price of land plus infrastructure

\pm The lower infrastructure price in Brasilia, as compared to the other two cities can be attributed to exorbitantly high prices of unserviced land. Since infrastructure is not a problem in Brasilia, a higher price for serviced land reflects the distortion in market for unserviced land.

\section{Table 2: Estimated Equilibrium Parameter Values}

\begin{tabular}{|l|l|l|l|l|}
\hline \multirow{2}{*}{ Parameters } & \multicolumn{1}{|c|}{ Description } & \multicolumn{3}{c|}{ Values } \\
\cline { 3 - 5 } & & Brasilia & Curitiba & Recife \\
\hline$\alpha$ & Share of land /house & 0.6 & 0.35 & 0.46 \\
\hline$\beta$ & Discount factor & 0.91 & 0.91 & 0.91 \\
\hline$r_{t}$ & Real loan rate & 0.099 & 0.099 & 0.099 \\
\hline$r_{\mathrm{dt}}$ & Real deposit rate & 0.027 & 0.027 & 0.027 \\
\hline$\xi_{1}$ & Share of Infrastructure/quality & 0.03 & 0.4 & 0.28 \\
\hline$\xi_{2}$ & Share of land/quality & 0.58 & 0.21 & 0.33 \\
\hline$\xi_{3}$ & Share of building/quality & 0.39 & 0.39 & 0.39 \\
\hline
\end{tabular}


Table 3: Steady state Values of the variables per unit of housing

\begin{tabular}{|l|l|l|l|l|}
\hline Variables & Description & \multicolumn{3}{|c|}{ Values } \\
\cline { 3 - 5 } & & Brasilia & Curitiba & Recife \\
\hline$Q$ & Quality of housing & 3540.94 & 5704.85 & 4771.33 \\
\hline$L$ & Average land area per house & 0.935 & 1.497 & 1.256 \\
\hline$B$ & Average building structure per house & 0.934 & 1.518 & 1.261 \\
\hline$R$ & Infrastructure per house & 8.989 & 0.539 & 0.554 \\
\hline
\end{tabular}

Note: For easy comparison of different situations with respect to the equilibrium as base, we standardize the value of land, building and infrastructure with respect to their availability per unit of house. For example, the unit of building structure available per unit house is 32 square $\mathrm{mt}$ (based on the source mentioned at the bottom of Table 1). We consider it as unit building structure. Similarly for land and infrastructure across three cities.

Table 4: In Situ Programs with Different Quality Equivalence Targets and Resource Requirements per unit of house (Distance $=1$ mile from the center)

\begin{tabular}{|l|l|l|l|}
\hline Resource requirement per unit of house & Brasilia & Curitiba & Recife \\
\hline For a quality equivalence, $\mathbf{k}=1.25$ & 1.373 & 4.332 & 2.469 \\
\hline Land & 1.655 & 2.689 & 2.235 \\
\hline Building structure & $1.5_{\mathrm{E}}{ }^{4}$ & 0.941 & 1.228 \\
\hline Infrastructure & 1.880 & 10.321 & 4.291 \\
\hline For a quality equivalence, $\mathbf{k = 1 . 5}$ & 2.642 & 4.293 & 3.566 \\
\hline Land & $6.6_{\mathrm{E}}{ }^{6}$ & 1.484 & 2.355 \\
\hline Building structure & 2.453 & 21.505 & 6.845 \\
\hline Infrastructure & 3.922 & 6.373 & 5.295 \\
\hline For a quality equivalence, k=1.75 & $1.1_{\mathrm{E}}{ }^{9}$ & 2.182 & 4.085 \\
\hline Land & \multicolumn{1}{|l|}{} \\
\hline Building structure &
\end{tabular}

Note: See note with Table-3 for details about unit of each resource 
Table 5: Social Welfare gain per Real spent on each of the following interventions for Different values of Quality Equivalence

\begin{tabular}{|c|c|c|c|c|c|c|}
\hline \multicolumn{7}{|c|}{ (Distance $=1$ mile from the center) } \\
\hline Social Welfare gain per Real spent on & Brasilia & & Curitiba & & Recife & \\
\hline \multicolumn{7}{|l|}{ For a quality equivalence, $\mathrm{k}=1.25$} \\
\hline Land & 61.448 & (2) & 56.603 & (2) & 62.071 & (2) \\
\hline Building structure & 76.419 & (1) & 49.771 & (3) & 58.672 & (3) \\
\hline Infrastructure & 0.124 & (3) & 139.460 & (1) & 150.201 & (1) \\
\hline \multicolumn{7}{|l|}{ For a quality equivalence, $\mathrm{k}=1.5$} \\
\hline Land & 53.848 & (2) & 26.936 & (3) & 41.358 & (3) \\
\hline Building structure & 57.458 & (1) & 35.359 & (2) & 42.562 & (2) \\
\hline Infrastructure & 0.000 & (3) & 100.241 & (1) & 90.677 & (1) \\
\hline \multicolumn{7}{|l|}{ For a quality equivalence, $\mathrm{k}=1.75$} \\
\hline Land & 48.161 & (1) & 15.963 & (3) & 31.348 & (3) \\
\hline Building structure & 45.148 & (2) & 29.405 & (2) & 34.664 & (2) \\
\hline Infrastructure & 0.000 & (3) & 84.189 & (1) & 63.229 & (1) \\
\hline
\end{tabular}

Note: Figures in the parentheses indicate the respective rankings of each policy based on social welfare to cost ratio.

Highest value indicates most preferred as an intervention.

\section{Table 6: Resource Requirements for Relocating Households at Various Distances} from the Center

(Quality Equivalence, $\mathrm{k}=1.25$ )

\begin{tabular}{|c|c|c|c|}
\hline Resource requirement per unit of house & Brasilia & Curitiba & Recife \\
\hline \multicolumn{4}{|l|}{ In situ Upgrading, $\mathrm{D}=1$ mile around center } \\
\hline Land & 1.373 & 4.332 & 2.469 \\
\hline Building structure & 1.655 & 2.689 & 2.235 \\
\hline Infrastructure & $1.5_{\mathrm{E}}^{4}$ & 0.941 & 1.228 \\
\hline \multicolumn{4}{|c|}{ For Relocation to a Distance, $\mathrm{D}=2.5$ miles away from center } \\
\hline Land & 3.025 & 38.385 & 9.898 \\
\hline Building structure & 5.358 & 8.707 & 7.234 \\
\hline Infrastructure & $6.5_{\mathrm{E}}^{10}$ & 2.958 & 6.308 \\
\hline \multicolumn{4}{|c|}{ For Relocation to a Distance, $D=5$ miles away from center } \\
\hline Land & 5.499 & 199.941 & 28.290 \\
\hline Building structure & 13.031 & 21.175 & 17.592 \\
\hline Infrastructure. & $6.8_{\mathrm{E}}^{15}$ & 7.036 & 21.748 \\
\hline \multicolumn{4}{|c|}{ For Relocation to a Distance, $\mathrm{D}=7.5$ miles away from center } \\
\hline Land & 7.799 & 525.007 & 52.292 \\
\hline Building structure & 21.915 & 35.611 & 29.585 \\
\hline Infrastructure & $5.8_{\mathrm{E}}^{18}$ & 11.679 & 44.861 \\
\hline
\end{tabular}

Note: See note with Table-3 for details about unit of each resource 
Table 7: Social Welfare gain per Real spent on each following resource for In Situ and Relocation Programs $(k=1.25)$

\begin{tabular}{|c|c|c|c|c|c|c|}
\hline \multicolumn{7}{|c|}{ Social Welfare gain per Real spent on } \\
\hline \multicolumn{7}{|c|}{ In situ Upgrading ( $\mathrm{D}=1$ mile around center) } \\
\hline Land & 61.448 & $(2)$ & 56.603 & $(2)$ & 62.071 & $(2)$ \\
\hline Building structure & 76.419 & $(1)$ & 49.771 & (3) & 58.672 & (3) \\
\hline Infrastructure & 0.124 & $(3)$ & 139.460 & $(1)$ & 150.201 & $(1)$ \\
\hline \multicolumn{7}{|l|}{ Relocation at $\mathrm{D}=2.5$ mile around center } \\
\hline Land & 27.89 & $(1)$ & 6.39 & $(3)$ & 15.49 & $(3)$ \\
\hline Building structure & 23.61 & (2) & 15.37 & (2) & 18.12 & (2) \\
\hline Infrastructure & 0.00 & (3) & 44.36 & (1) & 29.25 & $(1)$ \\
\hline \multicolumn{7}{|l|}{ Relocation at $\mathrm{D}=5$ mile around center } \\
\hline Land & 18.41 & (1) & 1.47 & (3) & 6.50 & (3) \\
\hline Building structure & 11.65 & $(2)$ & 7.59 & $(2)$ & 8.94 & (2) \\
\hline Infrastructure & 0.00 & (3) & 22.38 & $(1)$ & 10.18 & $(1)$ \\
\hline \multicolumn{7}{|l|}{ Relocation at $\mathrm{D}=7.5$ mile around center } \\
\hline Land & 15.15 & (1) & 0.65 & (3) & 4.10 & (3) \\
\hline Building structure & 8.08 & $(2)$ & 5.26 & $(2)$ & 6.20 & (1) \\
\hline Infrastructure & 0.00 & (3) & 15.73 & (1) & 5.76 & (2) \\
\hline
\end{tabular}

Note: Figures in the parenthesis indicate respective rankings of welfare programs.

Table 8: Social Welfare gain per Real spent and ranking of interventions under relocation policy with land supply constraint

(Relocation Distance=2.5 miles from the center, Quality Equivalence, $\mathrm{k}=1.25$ )

\begin{tabular}{|l|ll|ll|l|l|l|}
\hline Social Welfare gain per Real spent on & \multicolumn{2}{|l|}{ Brasilia } & \multicolumn{4}{l|}{ Curitiba } & Recife \\
\hline Land Availability =75 \% of the Equilibrium Amount & 49.818 & $(1)$ & 42.629 & $(2)$ & 45.995 & $(2)$ \\
\hline Building structure & 0.000 & $(2)$ & 119.909 & $(1)$ & 107.009 & $(1)$ \\
\hline Infrastructure & 27.259 & $(1)$ & 34.267 & $(2)$ & 32.637 & $(2)$ \\
\hline Land Availability =50 \% of the Equilibrium Amount & 0.000 & $(2)$ & 96.918 & $(1)$ & 66.356 & $(1)$ \\
\hline Building structure & 9.724 & $(1)$ & 23.593 & $(2)$ & 18.155 & $(2)$ \\
\hline Infrastructure & 0.000 & $(2)$ & 67.354 & $(1)$ & 29.315 & $(1)$ \\
\hline Land Availability =25 \% of the Equilibrium Amount
\end{tabular}




\section{Table 9: Resource Requirements under relocation policy with Land Supply Constraint}

(Relocation Distance=2.5 miles from the center, Quality Equivalence, $\mathrm{k}=1.25$ )

\begin{tabular}{|l|l|l|l|}
\hline Resource requirement per house & Brasilia & Curitiba & Recife \\
\hline Land Availability =75 \% of the Equilibrium Amount & 8.220 & 10.166 & 9.227 \\
\hline Building structure & $1.7_{\mathrm{E}}^{13}$ & 3.440 & 8.854 \\
\hline Infrastructure. & 15.022 & 12.647 & 13.004 \\
\hline Land Availability =50 \% of the Equilibrium Amount & $4.3_{\mathrm{E}}^{16}$ & 4.257 & 14.277 \\
\hline Building structure & 42.112 & 18.369 & 23.378 \\
\hline Infrastructure & $2.8_{\mathrm{E}}^{22}$ & 6.125 & 32.317 \\
\hline Land Availability =25 \% of the Equilibrium Amount \\
\hline Building structure
\end{tabular}

Note: See note with Table-3 for details about unit of each resource

Table 10: Degree of Credit Rationing and Equilibrium Supply of Land

\begin{tabular}{|l|l|l|l|}
\hline Credit Rationing & \multicolumn{3}{l|}{ Land Supply } \\
\hline & Brasilia & Curitiba & Recife \\
\hline Rationing $=10 \%$ & 1.00 & 1.595 & 1.353 \\
\hline Rationing $=25 \%$ & 0.996 & 1.586 & 1.346 \\
\hline Rationing $=50 \%$ & 0.981 & 1.559 & 1.322 \\
\hline Rationing $=75 \%$ & 0.934 & 1.483 & 1.258 \\
\hline
\end{tabular}


Figure 1: Effect of Distance on infrastructure-land lot relationship

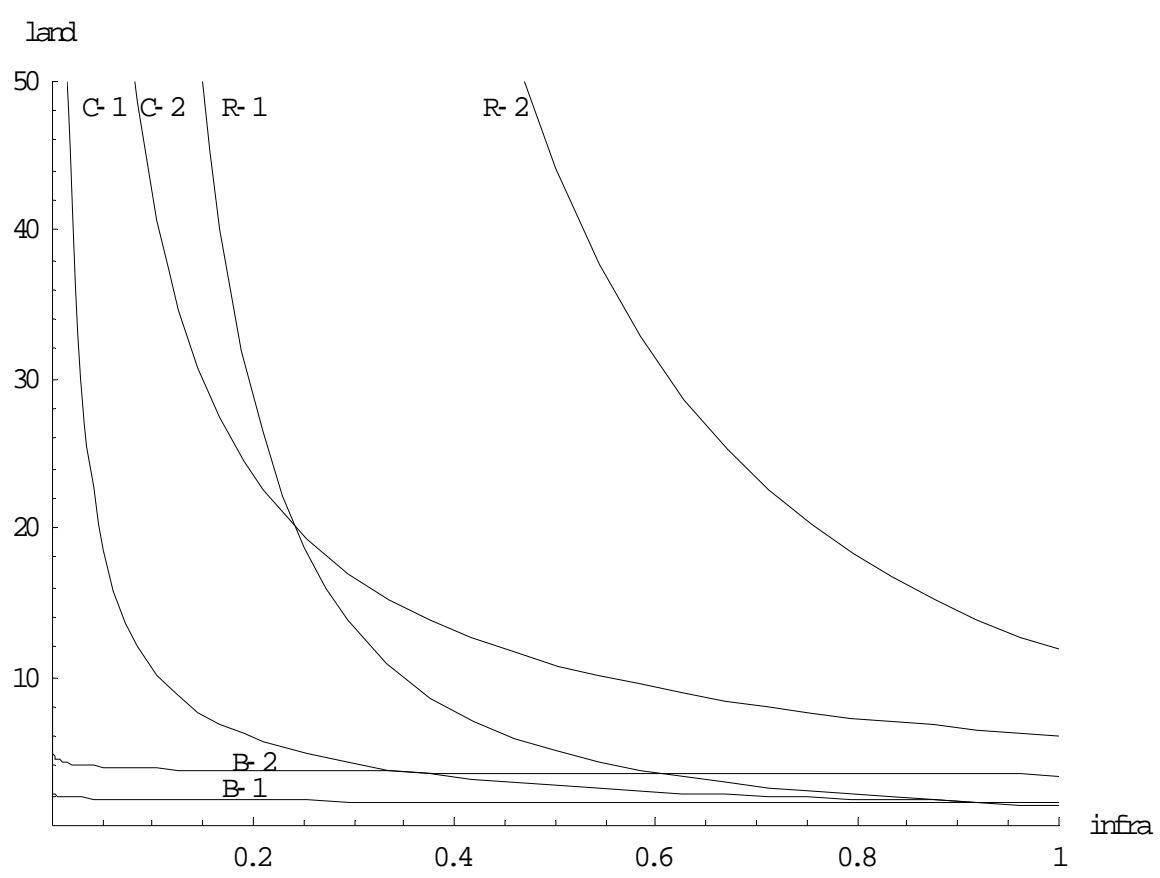

Note: B-1, C-1 and R-1 represent equilibrium relationship in Brasilia, Curitiba and Recife where as B-2, C-2 and R-2 represent the situation when the households are relocated to a distance 2.5 miles from their present locations.

\section{Figure 2: Effect of land constraint on Building-distance relationship}

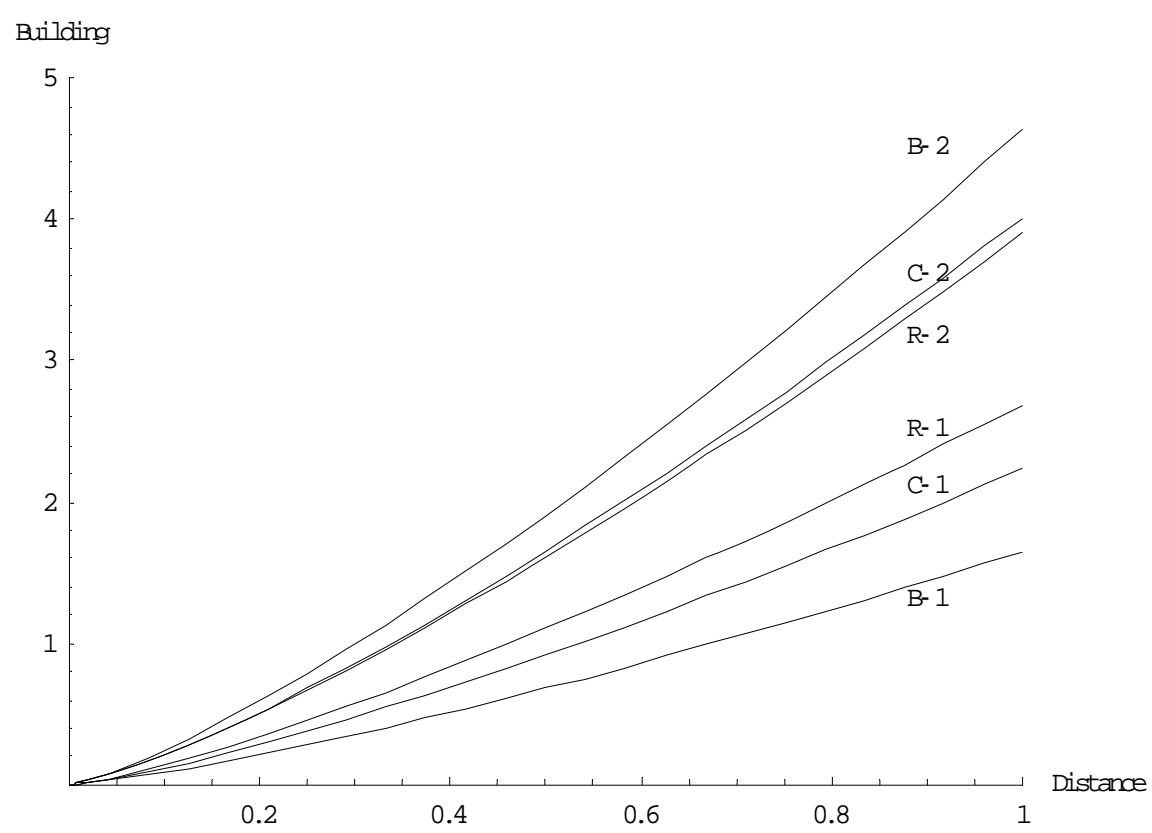

Note: B-1, C-1 and R-1 represent equilibrium relationship between building with distance in Brasilia, Curitiba and Recife where as B-2, C-2 and R-2 represent the situation when the land availability is constrained. 
Figure 3: Change in Demand for Infrastructure with Distance under land Market Distortion

\section{Infr}

5

1

2

3

4

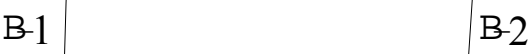

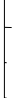

0.2

0.4

0.6

0.8

1

G2

R2

C1 1

Note: B-1, C-1 and R-1 represent equilibrium relationship between demand for infrastructure with distance in Brasilia, Curitiba and Recife. Their shifts to B-2, C-2 and R-2 represent the situation when the land availability is constrained.

\section{Figure 4: Supply of Land under Credit Rationing}

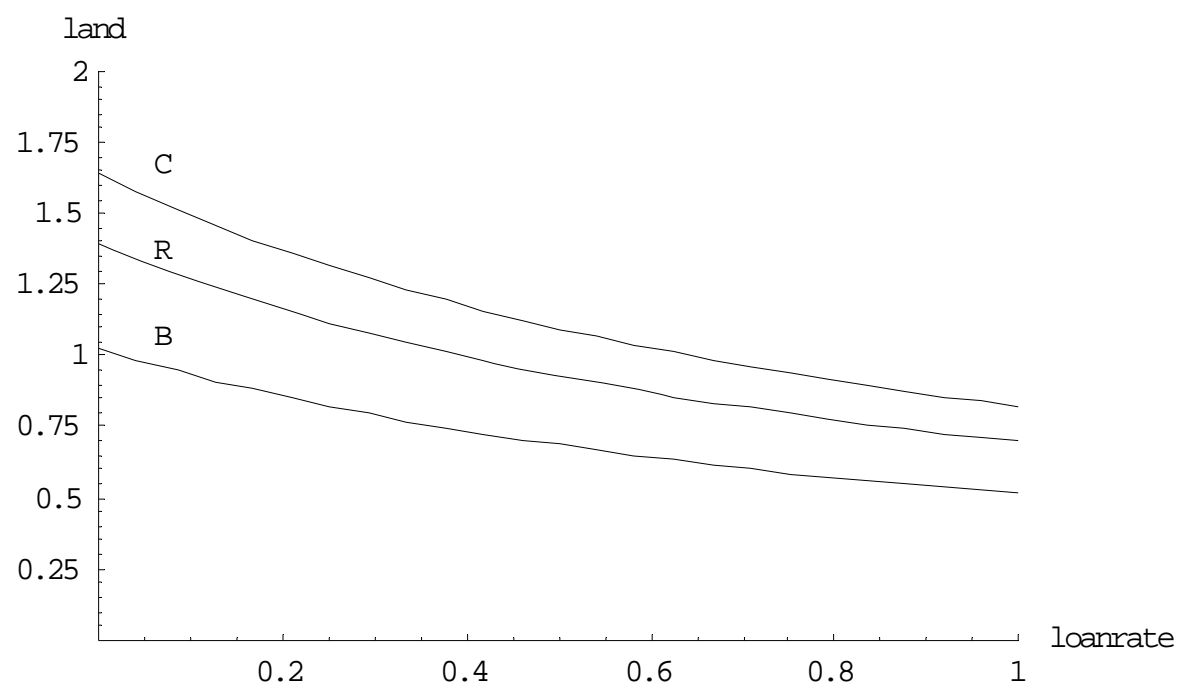

Note: B-1, R-1 and C-1 represents land supply in Brasilia, Recife and Curitiba respectively. 
Figure 5: Credit Rationing and Demand for Land

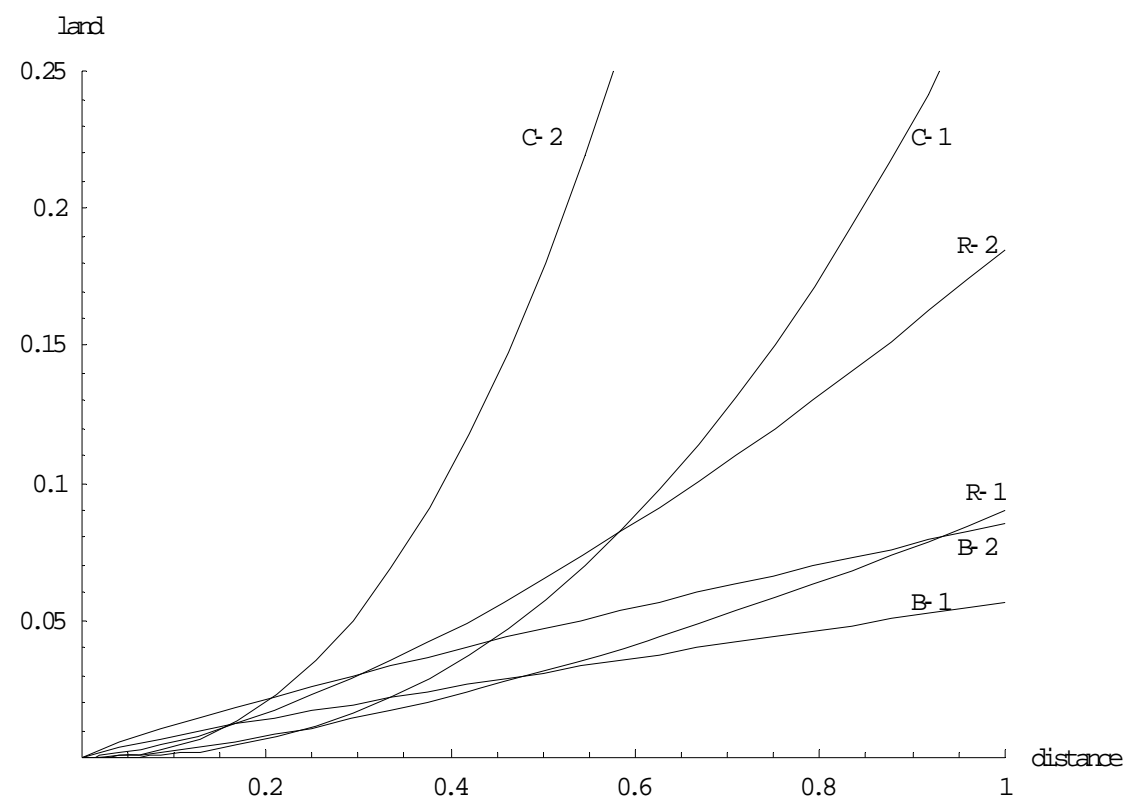




\section{APPENDIX: Methodology for measuring social welfare}

With assumption of no growth, we estimate the ratios of social welfare (based on Equation (22)) to their corresponding project implementation cost. In the following part of our analysis, we quantify the changes in the demand for land (L), building structure (B) or infrastructure (A) to maintain a range of specified quality standards. With our assumption of perfectly competitive factor markets, we estimate the corresponding cost of each quality enhancement project by multiplying resource requirements by their fixed price. The best policy is obtained from the rankings of social welfare to project cost ratio for each intervention.

As mentioned earlier, we measure the required social welfare enhancement in terms of quality equivalence. Using the lifetime utility maximization, the following equation measures the social welfare ${ }^{14}$ as

$S W=\frac{1}{1-\beta} \ln (\underline{C}+q)$

where, $\mathrm{SW}$ is social welfare, $\underline{\mathrm{C}}$ is minimum required consumption of non-housing goods, and $\mathrm{q}$ is the quality of housing services in the equilibrium.

Let us assume that the government decides to improve welfare from our specified substandard levels, termed as $\mathrm{q}_{s}$, to the equilibrium level of quality. With no leakages, the government has to improve existing substandard quality $\left(\mathrm{q}_{\mathrm{s}}\right)$ by $k$ times to reach the equilibrium utility. Given other parameter values, it turns out that $k q_{s}=q$. The coefficient, $k$, represents the quality equivalence of the set target with respect to the equilibrium quality such that

\footnotetext{
${ }^{14}$ The assumption of representative household leads social welfare as equivalent to individual household's welfare and overcome the aggregation problem.
} 
$\frac{1}{\beta} \ln \left[\underline{C}+k q_{s}\right]=\frac{1}{\beta} \ln [\underline{C}+q]$

Where, $q$ represents the equilibrium value of housing quality. Now, the government can achieve this quality improvement by choosing a set of interventions. When quality is enhanced, the ordering of alternate interventions leads us to the optimal level of land (L), building (B) and infrastructure (A), which is required individually to reach the equilibrium set from the inferior situation with quality $q_{s}$. Given the availability of these interventions, the relative rank ordering decides the government's adoption of alternate programs to enhance quality. From Equation (23) we get the requirement for each resource to reach the equilibrium level of quality as follows:

$$
\begin{aligned}
& L=\left[\frac{k D^{\gamma-1}}{A^{\xi_{1}} B^{\xi_{3}}}\right]^{\frac{1}{\xi_{2}}} \\
& A=\left[\frac{k D^{\gamma-1}}{L^{\xi_{2}} B^{\xi_{3}}}\right]^{\frac{1}{\xi_{1}}} \\
& B=\left[\frac{k D^{\gamma-1}}{A^{\frac{\xi_{1}}{\xi_{1}}} L^{\xi_{2}}}\right]^{\frac{1}{\xi_{3}}}
\end{aligned}
$$

Notice that the above functional relationships represent the requirements of each intervention to achieve the long run steady state quality when other resources are set at their equilibrium value. The Appendix shows how the final form of these equations are obtained.

As we find from the hedonic models explained in the literature, that $q_{t}=q_{t-1} A_{t}^{\xi_{1}} L_{t}^{\xi_{2}} B_{t}^{\xi_{3}} D_{t}^{1-\gamma}$

Where $q_{t}$ is quality in period $t, A_{t}, L_{t}, B_{t}$ and $D_{t}$ are the resources with the same meaning as discussed in households' optimization problem. 
Now, consider that in period $t-1$, the household is in sub optimal situation with quality qs (i.e., $\mathrm{q}_{\mathrm{s}}=\mathrm{q}_{\mathrm{t}-1}$ ). The government targets to pull up the household from this level to the equilibrium quality, $\mathrm{q}_{\mathrm{t}}$, in period $t$ by enhancing quality $k$ times. when the equilibrium has a quality equivalence of say, $\mathrm{k}$, then

$\mathrm{q}_{\mathrm{t}}=\mathrm{k} \mathrm{q} \mathrm{t}-1$

Replacing $\mathrm{q}_{\mathrm{t}}$ from the first equation we get

$$
\begin{aligned}
& k=A_{t}^{\xi_{1}} L_{t}^{\xi_{2}} B_{t}^{\xi_{3}} D_{t}^{1-\gamma} \\
& L_{t}=\left(\frac{k D^{\gamma-1}}{A^{\xi_{1}} B^{\xi_{3}}}\right)^{\frac{1}{\xi_{2}}}
\end{aligned}
$$

Given $\mathrm{Bt}$ and $\mathrm{A}_{t}$ at their equilibrium level. Same explanation applies to the other resources also. 